\title{
Effect of inhibitors on the electrochemical corrosion of heat- resistant ceramic coatings deposited on non-alloy steel
}

\section{A.V. Efimov, E.V. Kharanzhevskiy,* S.M. Reshetnikov, (iD T.A. Pisareva and M.G. Gotsuk}

\author{
Udmurt State University, ul. Universitetskaya, 1, 426034 Izhevsk, Russian Federation \\ *E-mail:eh@udsu.ru
}

\begin{abstract}
The corrosion resistance and electrochemical behavior of heat-resistant metal-matrix composites (MMCs) obtained by high-speed laser synthesis and deposited on the surface of nonalloy steel have been studied. It has been shown that the corrosion resistance of the coatings thus obtained can be improved by applying some corrosion inhibitors prior to coating. Four variants of the original powder mixture were studied, which were subjected to high-speed pulsed laser irradiation after applying on the surface of non-alloy steel. The original powder mixture contained various concentrations of finely dispersed zirconium dioxide, boron carbide, silicon carbide, and boron nitride combined with nickel powder. Depending on the concentration of these components, an MMC layer up to $20 \mu \mathrm{m}$ thick was produced in the course of laser treatment. The coatings thus obtained have high strength and wear resistance, low friction coefficient, and high level of adhesion to the substrate. The phase composition of the coatings was studied by X-ray single crystal analysis. The corrosion resistance and electrochemical behavior of samples were studied by anodic polarization under potentiodynamic conditions in a neutral buffer solution. It has been shown that the corrosion resistance of some samples should be enhanced. The effect of various inhibitors preliminarily deposited on the surface of samples on their corrosion resistance and electrochemical behavior was studied. The results of this study reveal a special effect of various inhibitors, which is related with the specific features of the coating composition, structure, and characteristics. The following inhibitors exhibited high efficiency: benzotriazole (BTA), potassium dichromate, and perhydropolysilazane. The technique of impregnating samples with solutions of the above inhibitors was used. Perhydropolysilazane was applied on sample surfaces with a brush.
\end{abstract}

Keywords: ceramic coating, boron and silicon carbides, boron nitride, zirconium borides, zirconium oxides, inhibitor treatment.

Received: June 1, 2021. Published: June 22, 2021

doi: $\underline{10.17675 / 2305-6894-2021-10-2-22}$

\section{Introduction}

Attention has been focused lately on the search for new techniques for application of coatings made of materials with an enhanced combination of mechanical and protective properties. The majority of items in machine engineering are manufactured from various steels and ironcontaining alloys. To improve the operational characteristics of these items, efficient 
technologies are needed for application of ceramic coatings that enhance strength, resistance to abrasive wear, and thermal resistance and reduce the coefficient of friction. Such coatings ensure that units remain operative in emergency situations involving a fast increase in temperature and provide protection against adhesive wear and seizure of sliding surfaces under oil starvation conditions $[1,2]$.

Zirconium diboride $\left(\mathrm{ZrB}_{2}\right)$ is among the primary materials for the production of ultrahigh-temperature ceramics owing to a unique combination of high thermal resistance, strength, high electric and thermal conductivity, and corrosion and erosion resistance $[3,4]$. Addition of silicon carbide to $\mathrm{ZrB}_{2}$-based ceramics enhances the thermal resistance due to formation of a protective film that comprises silicon and zirconium oxides. Zirconium diboride can be synthesized from its constituent elements at temperatures above $2000 \mathrm{~K}$. A disadvantage of this method lies in the extremely high rate of heating due to the exothermic reaction between $\mathrm{Zr}$ and $\mathrm{B}$, as a result of which the reaction does not occur to completion and material porosity develops.

The most popular method to synthesize high-temperature $\mathrm{ZrB}_{2}$-based ceramics is to reduce zirconium oxide with boron carbide. The components react at a temperature above $1600^{\circ} \mathrm{C}$ by the following reaction [5]

$$
2 \mathrm{ZrO}_{2}+\mathrm{B}_{4} \mathrm{C}+3 \mathrm{C} \rightarrow 2 \mathrm{ZrB}_{2}+4 \mathrm{CO}
$$

This method requires an excess of boron carbide since a fraction of boron is oxidized in a side reaction that accompanies reaction (1). The formation of zirconium carbide, $\mathrm{ZrC}$, as a side product is also observed in reaction (1), but its amount is relatively small if an excess of $\mathrm{B}_{4} \mathrm{C}$ (no more than 25\%) over the stoichiometric amount is used in the synthesis. $\mathrm{ZrB}_{2}$ can also be synthesized using boron nitride by the following reaction [3]:

$$
2 \mathrm{ZrO}_{2}+4 \mathrm{BN}+2 \mathrm{C} \rightarrow 2 \mathrm{ZrB}_{2}+2 \mathrm{CO}+2 \mathrm{~N}_{2}
$$

The synthesis is carried out in vacuo at a temperature above $1550^{\circ} \mathrm{C}$. Decreasing the synthesis temperature allows the size of zirconium diboride grains to be diminished, which positively affects the mechanical properties of ultrahigh-temperature ceramics. The use of hexagonal boron nitride (h-BN) allows reaction (2) to occur on the entire surface of $\mathrm{ZrO}_{2}$ particles, since the hexagonal structure of h-BN resembles that of graphite, so h-BN particles may be milled to speed up the synthesis.

The application of ceramic materials on metal substrates allows the physical and mechanical properties of the surface of products to be improved. Such materials are most suitable for operational conditions where high temperatures may occur for a short time [6, 7], for example, in the case of operations involving enhanced surface wear or degradation. Study [7] compares the structures and mechanical properties of $\mathrm{ZrB}_{2}$-based coatings with those of $\mathrm{SiC}$ coatings in which nickel is used as a binding agent. It is shown that such coatings are very promising.

The physical and mechanical properties of such materials, in particular, their thermal resistance, resistance to oxidation, and effect of water vapors at elevated temperatures are 
explored in a number of studies (see, for example, $[2,3,7]$ ). However, there are nearly no publications dealing with studies on the corrosion resistance of coatings based on zirconium diboride or boron carbide on steels under electrochemical corrosion conditions. As shown in study [8], atmospheric and electrochemical corrosion may develop faster in areas where a steel substrate contacts carbide- or boron-based ceramic materials. The same study also reports a negative effect of boride and carbide particles on the anticorrosion properties of steel. In view of this, a study on the properties of phases formed in zirconium diboride or silicon carbide based systems in a broad range of potentials is of importance, since the effects of the carbide and boride phases on the corrosion resistance of these systems may crucially depend on the range of potentials and the type of the corrosive medium [9].

In this work we study the corrosion resistance and electrochemical behavior of samples with applied MMC coatings based on zirconium diboride synthesized by different methods, as well as silicon carbide. It should be noted that the applied phases themselves have fairly high corrosion resistance, both at high temperatures and in electrolyte solutions $[10,11]$. However, due to the presence of pores, cracks, and other defects in a solid ceramic coating, the substrate material, i.e., non-alloy low-carbon steel, is subject to electrochemical corrosion.

\section{Experimental}

Solid-phase metal-matrix composites with four various compositions were applied on Steel 10 substrates with dimensions of $10 \times 10 \times 1 \mathrm{~mm}$. The compositions of the powder mixtures for coating, the phase compositions of the coatings formed as a result of laser synthesis, and the main reactions that occur are presented in Table 1.

The composition of all the coatings provides high thermal resistance, hardness, and antifriction properties of the surface under conditions of dry sliding friction under high contact loads [2]. The selected composition of the powder mixtures and the resulting phase composition of the coatings allows one to estimate the effect of the following factors on electrochemical corrosion: (a) excess of boron carbide - composition 1; (b) addition of silicon carbide to $\mathrm{ZrB}_{2}$-based ceramic - composition 2; and (c) the method for zirconium oxide reduction by a combination of reactions (1) and (2) - composition 3. Composition 4 allowed us to study the electrochemical corrosion of ceramic coatings mostly containing only silicon carbide. To apply the coatings, a powder consisting of PNK-grade nickel with a particle size up to $10 \mu \mathrm{m}, \mathrm{F} 5$-grade boron carbide with a particle size up to $5 \mu \mathrm{m}$, hexagonal boron nitride with disc-shaped particles with a diameter of up to $5 \mu \mathrm{m}$ and a thickness of up $140 \mathrm{~nm}$, and silicon carbide with with a particle size up to $10 \mu \mathrm{m}$ was used. 
Table 1. Compositions of powder mixtures and qualitative compositions of coatings formed by high-speed short-pulse laser synthesis.

\begin{tabular}{|c|c|c|c|c|}
\hline Description & $\begin{array}{c}\text { Composition } \\
\text { of powder } \\
\text { mixture (wt \%) }\end{array}$ & $\begin{array}{l}\text { Qualitative phase composition } \\
\text { of coatings }{ }^{1}\end{array}$ & $\begin{array}{l}\text { Main } \\
\text { reactions }\end{array}$ & $\begin{array}{c}\text { Microhardness, } \\
\text { HV }\end{array}$ \\
\hline Composition 1 & $\begin{array}{c}\mathrm{Ni}-\text { base } \\
\mathrm{ZrO}_{2}-20 \% \\
\mathrm{~B}_{4} \mathrm{C}-7 \%\end{array}$ & $\mathrm{ZrB} 2-\mathrm{Ni}-\mathrm{ZrO}_{2}-\mathrm{B}_{4} \mathrm{C}-\mathrm{Fe}_{3} \mathrm{~B}$ & $(3),(5)$ & 1150 \\
\hline Composition 2 & $\begin{array}{c}\mathrm{Ni}-\text { base } \\
\mathrm{ZrO}_{2}-40 \% \\
\mathrm{~B}_{4} \mathrm{C}-6 \% \\
\mathrm{SiC}-10 \%\end{array}$ & $\mathrm{ZrB}_{2}{ }^{(*)}-\mathrm{Ni}-\mathrm{ZrO}_{2}-\mathrm{B}_{4} \mathrm{C}$ & (3) & 1700 \\
\hline Composition 3 & $\begin{array}{c}\mathrm{Ni}-\text { base } \\
\mathrm{ZrO}_{2}-20 \% \\
\mathrm{~B}_{4} \mathrm{C}-4 \% \\
\mathrm{BN}-1 \% \\
\mathrm{SiC}-6 \%\end{array}$ & $\begin{array}{c}\mathrm{ZrB}_{2}-\mathrm{Ni}-\mathrm{ZrO}_{2}-\mathrm{B}_{4} \mathrm{C}-\mathrm{Ni}_{3} \mathrm{~N}- \\
\mathrm{ZrC}-\mathrm{Fe}_{3} \mathrm{~B} \text { (traces) }\end{array}$ & $\begin{array}{c}(3),(4),(5), \\
(6)\end{array}$ & 1200 \\
\hline Composition 4 & $\begin{array}{l}\mathrm{Ni}-\text { base } \\
\mathrm{ZrO}_{2}-7 \% \\
\mathrm{SiC}-15 \%\end{array}$ & $\mathrm{SiC}^{(*)}-\mathrm{Ni}-\mathrm{ZrO}_{2}^{(*)}-\mathrm{ZrC}$ & - & 780 \\
\hline
\end{tabular}

Notes:

${ }^{1}$ In the order of decreasing concentration of components in the MMC according to X-ray single crystal analysis and SEM. ${ }^{(*)} \mathrm{X}$-ray amorphous.

To apply the coatings, a laser facility based on an ytterbium fiber-optics laser with a maximum average power of $50 \mathrm{~W}$ and a wavelength of $1.065 \mu \mathrm{m}$ was used. A chamber with controlled atmosphere was used for laser synthesis. The chamber was purged with highpurity argon for $2 \mathrm{~min}$. Laser treatment was carried out using short (40 ns) pulses. This is three to four orders of magnitude longer than the relaxation time in the energy transfer from the valence electron gas that absorbs the laser radiation energy to the crystal lattice of the surface being treated [12]. Therefore, the effect of laser radiation energy on the ceramic powder can be described using the thermal conductivity mechanism. The short pulse duration provides ultrafast heating and a high temperature gradient in the treated area. The pulse frequency is $100 \mathrm{kHz}$ and the pulse energy is $0.5 \mathrm{~mJ}$. The calculated instantaneous power of the laser beam with these laser treatment parameters is $5 \mathrm{~kW}$. The laser beam was focused onto a spot $30 \mu \mathrm{m}$ in diameter; therefore, the instantaneous power density of laser radiation was $7 \cdot 10^{12} \mathrm{~W} / \mathrm{m}^{2}$. The scanning rate was $100 \mathrm{~mm} / \mathrm{s}$. Laser radiation modes were selected using the technique described in Ref. [13].

The microstructure and phase and chemical compositions of the MMC were studied using the following methods. X-ray single-crystal analysis was carried out using a DRON-3 
diffractometer with $\mathrm{Fe}-\mathrm{K} \alpha$ radiation. The intensity was collected for $5 \mathrm{~s}$ at each $2 \theta \mathrm{c}$ point with a step of $0.02^{\circ}$. The appearance of the coating surfaces was examined by scanning electron microscopy (SEM) using a FEI INSPECT S50 microscope. The microscope was equipped with an energy dispersive X-ray (EDX) detector that allowed one to monitor the chemical composition of coatings.

The corrosion resistance and electrochemical behavior of the samples were studied using anodic polarization under potentiodynamic conditions by the technique reported in Ref. [14]. The samples were polarized at a potential scan rate of $2 \mathrm{mV} / \mathrm{s}$. An Ipc-Pro L potentiostat and a standard YaSE-2 cell were used. The experiments were performed at the ambient temperature of $(20 \pm 2)^{\circ} \mathrm{C}$. A borate buffer solution with $\mathrm{pH} 7.4$ (BBR 7.4) was used as the model electrolyte. This electrolyte was chosen because borate ions are virtually indifferent with respect to the electrode materials, i.e., they neither convert them to the passive state nor activate them (passive state breakdown). Moisture can condense on a sliding surface during outages or discontinuities of operations, and as a result conditions for electrochemical corrosion may appear on the entire surface or on its individual structural elements. For this reason, the studies were carried out in the neutral model electrolyte described above, borate buffer solution with $\mathrm{pH} 7.4$ (BBS) under natural aeration conditions. It should be noted that operations of jet-prop engines (JPEs) with hard-alloy coatings do not result in electrochemical corrosion provided moisture does not condense. However, a thin moisture film of a condensate can appear on these parts during a parking or repair period. The condensate that forms in devices containing hard-metal coatings during a parking period is almost pure water. In view of this, BBS was used as the model medium. Electrode potentials were measured during polarization using a saturated silver chloride electrode. The results obtained are reported against that electrode.

\section{Results and Discussion}

The short duration of laser pulses provides high density of radiation energy, which results in high heating and cooling rates (of the order of $10^{7} \mathrm{~K} / \mathrm{s}$ ) and a high temperature gradient (about $10^{8} \mathrm{~K} / \mathrm{m}$ ). The temperature in a local zone near the powder/substrate interface increases at the heating stage to $3500^{\circ} \mathrm{C}$, a value that significantly exceeds the melting points of zirconium oxide $\left(2715^{\circ} \mathrm{C}\right)$ and boron nitride and carbide powders $\left(\mathrm{BN}-2973^{\circ} \mathrm{C}, \mathrm{B}_{4} \mathrm{C}-\right.$ $2350^{\circ} \mathrm{C}$ ) [15]. A computer simulation showed that concurrently with melting of the ceramic powder, a thin layer of the steel substrate about $20 \mu \mathrm{m}$ thick also melts. This limited depth of melting is due to the high temperature gradient in the irradiated area. The solidification front moves at the cooling stage after the laser pulse with a velocity of up to $2 \mathrm{~m} / \mathrm{s}$. These estimates follow from a computer simulation of the heat and mass transport processes performed by the technique reported in Ref. [16]. Due to intense stirring of the melt at high temperatures, ceramics and molten steel interact, which explains a high degree of adhesion of the coating to the substrate.

The appearance of coatings with four various MMC compositions is shown in Figure 1. As noted above, the composition of these coatings is displayed in Table 1. Large inclusions 
of boron carbide can be seen in Figure 1a (colored black), since powder mixture 1 contained an excess of $\mathrm{B}_{4} \mathrm{C}$ with respect to $\mathrm{ZrO}_{2}$ in comparison with the stoichiometric ratio of the following reaction:

$$
2 \mathrm{ZrO}_{2}+\mathrm{B}_{4} \mathrm{C} \rightarrow 2 \mathrm{ZrB}_{2}+\mathrm{CO}+\mathrm{B}_{2} \mathrm{O}_{3}
$$

In addition to the large $\mathrm{B}_{4} \mathrm{C}$ inclusions, a large number of inclusions with dimensions from 20 to $200 \mathrm{~nm}$ are observed. Composition 2 of the powder mixture contains less $\mathrm{B}_{4} \mathrm{C}$ with respect to $\mathrm{ZrO}_{2}$; therefore, the surface of the coatings obtained is more uniform (Figure $1 \mathrm{~b}$ ) and only contains inclusions of nanosized $\mathrm{B}_{4} \mathrm{C}$ and $\mathrm{SiC}$ particles. Addition of h$\mathrm{BN}$ to the powder mixture (composition 3 ) results in competing reactions of zirconium oxide reduction with boron carbide (3) along with the following reaction:

$$
\mathrm{ZrO}_{2}+2 \mathrm{BN} \rightarrow \mathrm{ZrB}_{2}+2 \mathrm{NO}
$$

The finely dispersed boron nitride powder provides better contact with zirconium oxide particles, and reduction of $\mathrm{ZrO}_{2}$ in two reactions, (3) and (4), results in a smooth surface of the ceramic coating on the steel substrate (see Figure 1c). The surface of a ceramic coating that only contains $\mathrm{SiC}$ is shown in Figure 1d. Due to the large content of silicon carbide, the viscosity of the melt increases, which is manifested in a non-smooth surface of the coating. It should be noted that all coatings with compositions $1-3$ that contain $\mathrm{ZrB}_{2}$ are characterized, albeit to various extent, by the presence of defects. The defects include microcracks in the coatings and pores; the number of defects decreases from composition 1 to composition 3. The coating made of composition 4 has no cracks.

The results of X-ray single crystal analysis of the coatings of all the MMCs studied are displayed in Figure 2. These results demonstrate the reduction of zirconium oxide according to reactions (3) or (4). The powder mixture with composition 2 is characterized by a decreased ratio of silicon carbide to zirconium oxide. Since reaction (3) is not completed, the resulting zirconium diboride is X-ray amorphous (Figure 2b), while the formation of zirconium boride is confirmed by the results of the EDX analysis of the content of elements in the coating. According to X-ray single-crystal analysis, the coatings with compositions 1 and 3 contain compounds that are formed in reactions of ceramic coating components with the steel substrate. For example, composition 1 is characterized by the following reaction:

$$
12 \mathrm{Fe}+\mathrm{B}_{4} \mathrm{C} \rightarrow 4 \mathrm{Fe}_{3} \mathrm{~B}+\mathrm{C},
$$

while composition 3, according to data of X-ray single-crystal analysis, contains products of the following reaction:

$$
3 \mathrm{Ni}+\mathrm{BN}+3 \mathrm{Fe} \rightarrow \mathrm{Ni}_{3} \mathrm{~N}+\mathrm{Fe}_{3} \mathrm{~B}
$$

The occurrence of reactions (5) and (6) upon short-pulse laser melting explains the high degree of adhesion of the resulting coatings to the steel substrate. The microhardness of the coatings with various compositions is shown in Table 1; the microhardness of the substrate itself is HV 200. 



Figure 1. SEM image of MMC samples with the following compositions: a - composition 1, $\mathrm{b}$ - composition 2, c-composition 3, d-composition 4 .

Summarizing the results of various analytical methods, the conclusion can be made that phases such as $\mathrm{ZrB}_{2}, \mathrm{Ni}, \mathrm{ZrO}_{2}, \mathrm{~B}_{4} \mathrm{C}, \mathrm{Ni}_{3} \mathrm{~N}, \mathrm{ZrC}$, and $\mathrm{Fe}_{3} \mathrm{~B}$ in the coating directly contact the steel substrate.

It is known from literature data that carbides, silicides, and borides of many metals obtained in a compact crystalline form by metallurgical technologies have high electrocatalytic activity and resistance to electrochemical corrosion. As qualitative analysis confirms, the $\mathrm{Fe}$ (II) and $\mathrm{Fe}$ (III) ions, i.e., the material from the non-alloy steel substrate, are the primary product of anodic attack. The elements from the MMC do not undergo dissolution under these conditions.

Various inhibitors were tested in preliminary studies for enhancing the corrosion resistance of the metal-matrix coatings developed. Samples were immersed in solutions that contained the inhibitors in the concentrations presented below, maintained for 30-40 min, and then dried in air under ambient conditions. The samples were then studied in the BBS using the potentiodynamic method. 



Figure 2. Results of X-ray single-crystal analysis of the MMC coatings: a - composition 1;

$\mathrm{b}$ - composition 2; c-composition 3; d-composition 4 .

Based on the results that we published earlier [8], the following compounds were studied as inhibitors: an aqueous solution of potassium dichromate (1M), an $1 \mathrm{M}$ alcohol solution of benzotriazole (BTA), and perhydropolysilazane.

Potassium dichromate is an oxidative inhibitor that facilitates the transition of materials, in particular those based on iron, into a stable passive state [17]. BTA is a blocking-type inhibitor that performs well in the protection of ferrous and nonferrous metals in aqueous media [18].

Perhydropolysilazane, an organic silicon compound that has strong hydrophobic properties similar to those of silanes and silazanes [19, 20], was also used as an inhibitor. On dissolution in water, this high-viscosity compound formed a colloid solution from which water was first adsorbed on the coating surface, while perhydropolysilazane remained on the surface and did not penetrate into the pores and other defects in the ceramics. For this reason, pure perhydropolysilazane was applied on the ceramics surface with a brush. The sample was then heated to reduce viscosity to $150^{\circ} \mathrm{C}$ where polymerization of perhydropolysilazane occurred, or to $380^{\circ} \mathrm{C}$, where perhydropolysilazane decomposed to give a thin film of silicon dioxide.

Figure 3 (a, b, c, d) displays the potentiodynamic polarization curves for the samples studied. The plots show that upon preliminary treatment of the samples with MMC coatings whose composition was described above a fairly broad passivation range appears on the anodic curves. The efficiency of the inhibitor layer was estimated by the anodic current 
density $i_{\mathrm{a}}, \mu \mathrm{A} / \mathrm{cm}^{2}$, at a potential of $E=400 \mathrm{mV}$. The potential at which a growth in the anodic current is attained, i.e., the transpassivation potential $E_{\mathrm{tp}}, \mathrm{mV}$, may also be used as a characteristic of the protective effect of the inhibitor layer. It should be noted that the higher the anodic potential where transpassivation starts, the better the protective properties of the inhibitor used to create the adsorption layer. The values of $i_{\mathrm{a}}$ and $E_{\mathrm{tp}}$ obtained are shown in Table 2 for comparison.

Table 2. Anodic currents $\left(i \mathrm{a}, \mu \mathrm{A} / \mathrm{cm}^{2}\right)$ at the passivation potential $(E=400 \mathrm{mV})$ and the transpassivation potentials $\left(E_{\mathrm{tp}}, \mathrm{mV}\right)$.

\begin{tabular}{|c|c|c|c|}
\hline & Sample, inhibitor & $i_{\mathrm{a},}, \mu \mathrm{A} / \mathrm{cm}^{2}$, at $E=400 \mathrm{mV}$ & $E_{\mathrm{tp}}, \mathbf{m V}$ \\
\hline \multirow{5}{*}{ MMC-1 } & Without inhibitor (2) & 55.77 & 672.68 \\
\hline & BTA (3) & 24.40 & 1011.53 \\
\hline & Potassium dichromate (4) & 8.09 & 1028.21 \\
\hline & Silazane $150^{\circ} \mathrm{C}(5)$ & 14.14 & 1041.98 \\
\hline & Silazane $380^{\circ} \mathrm{C}(6)$ & 52.3 & 188.70 \\
\hline \multirow{5}{*}{ MMC-2 } & Without inhibitor (2) & 11.7 & 1000.91 \\
\hline & BTA (3) & 17.47 & 1059.60 \\
\hline & Potassium dichromate (4) & 6.01 & 1023.51 \\
\hline & Silazane $150^{\circ} \mathrm{C}(5)$ & 14.01 & 1044.27 \\
\hline & Silazane $380^{\circ} \mathrm{C}(6)$ & 10.75 & 1101.00 \\
\hline \multirow{5}{*}{ MMC-3 } & Without inhibitor (2) & 48.51 & 696.59 \\
\hline & BTA (3) & 84.48 & 1027.29 \\
\hline & Potassium dichromate (4) & 11.51 & 928.78 \\
\hline & Silazane $150^{\circ} \mathrm{C}(5)$ & 24.11 & 1070.46 \\
\hline & Silazane $380^{\circ} \mathrm{C}(6)$ & 27.40 & 1049.41 \\
\hline \multirow{5}{*}{ MMC-4 } & Without inhibitor (2) & 4.36 & 1170.49 \\
\hline & BTA (3) & 7.21 & 1120.71 \\
\hline & Potassium dichromate (4) & 4.36 & 1132.38 \\
\hline & Silazane $150^{\circ} \mathrm{C}(5)$ & 2.74 & 1114.22 \\
\hline & Silazane $380^{\circ} \mathrm{C}(6)$ & 4.36 & 1093.87 \\
\hline
\end{tabular}



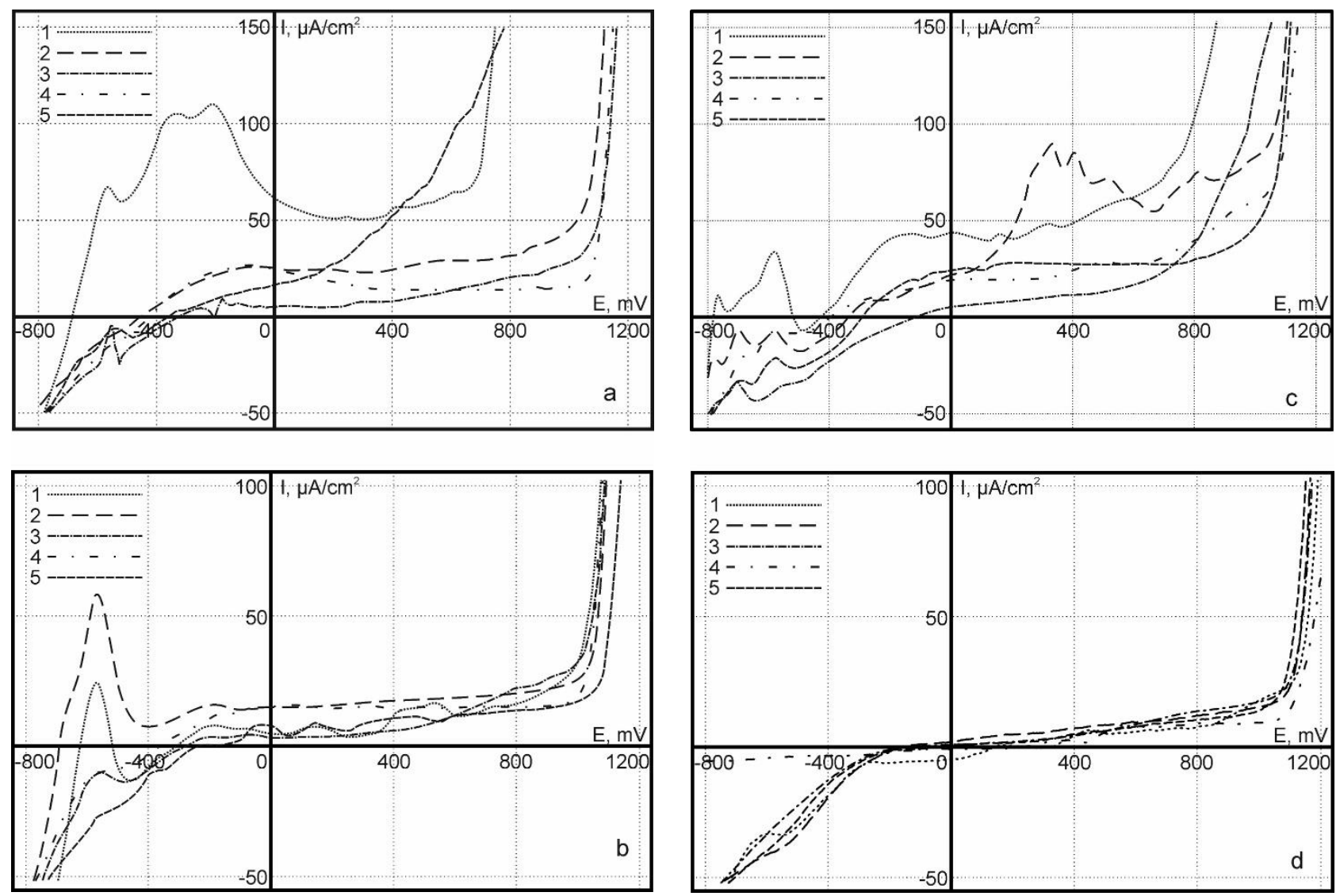

Figure 3. Curves of anodic potentiodynamic polarization of samples coated with MMC with composition 1 (a), 2 (b), 3 (c), 4 (d); numbering of the curves: 1 - without treatment with inhibitors; 2 - treated with 1 M BTA solution, 3 - treated with an $1 \mathrm{M}$ potassium dichromate solution, 4 - treated with perhydropolysilazane and heated to $150^{\circ} \mathrm{C}, 5-$ treated with perhydropolysilazane and heated to $380^{\circ} \mathrm{C}$.

Figure 3(a) displays the anodic potentiodynamic curves of the samples with coating 1. The figure shows that the sample with this coating has rather a high rate of anodic dissolution. The currents are much higher than $50 \mu \mathrm{A} / \mathrm{cm}^{2}$ even in the relatively narrow passive region.

The presence of BTA, an adsorption inhibitor, on coated samples significantly reduces the anodic dissolution rate (curve 2). The region that may be associated with active or prepassive dissolution of the sample nearly vanishes. The anodic potential where a growth in the anodic current due to transpassivation is observed also increases significantly.

Curve 3 shows that the protective effect of potassium dichromate, a passivating inhibitor, is pronounced even more clearly. Judging by the curve, the sample after treatment with a potassium dichromate solution passes into a passive state in the course of anodic dissolution.

As noted above, because of the high viscosity of perhydropolysilazane, it was applied with a brush on the sample surfaces. To reduce the viscosity of the applied layer and enhance its penetration into the coating pores, the sample was heated after coating with perhydropolysilazane to $150^{\circ} \mathrm{C}$ or $380^{\circ} \mathrm{C}$. It should be noted that perhydropolysilazane 
heated to $150^{\circ} \mathrm{C}$ remained in its original state, whereas at $380^{\circ} \mathrm{C}$ it polymerized. Curves 4 and 5 in the figure show that heating of the perhydropolysilazane-coated sample to $150^{\circ} \mathrm{C}$ reduces the anodic currents, virtually removes the pre-passive solution region, and increases the anodic potential where transpassivation occurs.

Heating of the sample impregnated with hydropolysilazane to $380^{\circ} \mathrm{C}$ reduces the efficiency of the protective layer. An explanation of this phenomenon may be that a silica frame is formed at this temperature, which does not facilitate blocking of the surface for this ceramic coating. The table shows that the smallest currents in the passive state and the widest region of passivation potentials are provided by the following inhibitors: perhydropolysilazane (heating to $150^{\circ} \mathrm{C}$ ) and potassium dichromate.

Figure 3(b) shows the anodic polarization curves of samples with composition 2. It is noteworthy that the anodic currents on these samples measured even in the absence of inhibitors are significantly smaller than in the previous case. Judging by the current density in the passive area, the highest efficiency is provided by inhibitors such as potassium dichromate and perhydropolysilazane heated to $380^{\circ} \mathrm{C}$. The maximum increase in the $E_{\mathrm{tp}}$ potential where transpassivation occurs is observed in the latter case. In this case, heating of the silane to $380^{\circ} \mathrm{C}$ apparently facilitates the formation of a sufficiently efficient protective layer. The other inhibitors (curves 3, 4, and 5) also exhibit high protection efficiency.

Figure 3(c) displays the anodic potentiodynamic curves for coating 3 . It should only be noted that the sample with coating 3 rather quickly attains the transpassivation potential without treatment with an inhibitor and shows a relatively high dissolution rate in the passive state. The figure also shows that the efficiency of BTA as an inhibitor is low. Although potassium dichromate reduces the anodic dissolution rate at passive state potentials, it only provides a small increase in the potential where transpassivation occurs. In this case, perhydropolysilazane is the optimal inhibitor for this coating provided that samples are impregnated at $150^{\circ} \mathrm{C}$. The efficiency of perhydropolysilazane with heating to $380^{\circ} \mathrm{C}$ is somewhat lower.

A similar situation is observed for samples 4 (Figure 3(d)). It follows from the figure that all anodic curves, both with and without the coating, show rather low anodic currents (7-8 times lower than those on the uncoated sample). All the inhibitors studied insignificantly affect the rate of the anodic process. The best results are obtained in the case of treatment with perhydropolysilazane at $150^{\circ} \mathrm{C}$.

In terms of electrochemical corrosion of the studied samples, the best results were shown by samples 4 . It may well be that this effect is due to the low porosity and impenetrability of coating 4 for the corrosion medium.

\section{Conclusions}

1. Heat-resistant metal-matrix composites were deposited on a substrate made of non-alloy steel using the high-speed laser synthesis method.

2. Four optimal compositions of the original powder mixture based on zirconium dioxide, boron and silicon carbides, and boron nitride combined with powdered nickel were 
studied. The porosity and hardness of the MMC layer formed in the course of laser treatment depend on the concentration of the components listed above.

3. The corrosion and electrochemical properties of the samples obtained were studied using potentiodynamic anodic polarization in a neutral borate buffer solution. Pretreatment of the samples under study with inhibitors such as potassium dichromate, benzotriazole, and perhydropolysilazane enhances the corrosion strength of the samples by increasing the anodic dissolution currents several-fold and extending the range of passive state potentials.

4. The most efficient technology is to impregnate the samples with perhydropolysilazane and subsequently heat them to $150^{\circ} \mathrm{C}$ for polymerization of perhydropolysilazane and enhancement of its penetration into the pores and defects of the MMC coating.

5. The application of MMC consisting of silicon carbide and zirconium oxide (composition 4) provides rather low anodic dissolution currents even without the use of inhibitors.

\section{Acknowledgements}

The authors are grateful to the Russian Science Foundation for financial support as part of project No. 19-79-20012.

\section{References}

1. E.V. Kharanzhevskiy, A.G. Ipatov, M.D. Krivilyov, A.V. Makarov, F.Z. Gil'mutdinov and E.G. Volkova, Ultralow friction behaviour of B4C-BN-MeO composite ceramic coatings deposited on steel, Surf. Coat. Technol., 2020, 390, 125664. doi: 10.1016/j.surfcoat.2020.125664

2. E.V. Kharanzhevskiy, A.G. Ipatov, A.V. Makarov, F.Z. Gil'mutdinov, N.N. Soboleva and M.D. Krivilyov, Tribological performance of boron-based superhard coatings sliding against different materials, Wear, 2021, 203835. doi: 10.1016/j.wear.2021.203835

3. C. Yan, R. Liu, C. Zhang, Y. Cao and X. Long, Synthesis of $\mathrm{ZrB}_{2}$ Powders from $\mathrm{ZrO}_{2}$, BN, and C, J. Am. Ceram. Soc., 2016, 99, no. 1, 16-19. doi: 10.1111/jace.14027

4. V.V. Malyshev, A.I. Gab, Physicochemical properties and electrodeposits based on Tungsten Carbide and zirconium diboride on steels, Prot. Met. Phys. Chem. Surf., 2007, 43, no. 1, 45-49.

5. P. Peshev and G. Bliznakov, On the Borothermic Preparation of Titanium, Zirconium and Hafnium Diborides, J. Less-Common Met., 1968, 14, 23-32.

6. T.A. Wolfla and R.C. Tucker, JR. High temperature wear-resistant coatings, Thin Solid Films, 1978, 53, 353-364.

7. X. Yan, X. Jin, P. Li, C. Hou, X. Hao, Z. Li and X. Fan, Microstructures and mechanical properties of $\mathrm{ZrB} 2-\mathrm{SiC}-\mathrm{Ni}$ ceramic composites prepared by spark plasma sintering, Ceram. Int., 2019, 45, no. 13, 16707-16712.

8. E.V. Kharanzhevskiy, S.M. Reshetnikov, A.V. Efimov, F.Z. Gil'mutdinov and M.D. Krivilev, Application of some inhibitors for improving the corrosion resistance of 
ceramic coatings deposited on non-alloy steel by short-pulse laser treatment, Int. J. Corros. Scale Inhib., 2020, 9, no. 1, 44-55. doi: 10.17675/2305-6894-2020-9-1-3

9. Y.M. Kolotyrkin and V.M. Knyazheva, Properties of carbide phases and corrosion resistance of stainless steels, Korroziya $i$ zashchita ot korrozii. Itogi nauki i tekhniki (Corrosion and Corrosion Protection. Advances in Science and Technology), Moscow, VINITI, 1974, vol. 3, 5-83 (in Russian).

10. A.V. Bogoyavlenskii, M.S. Tsirlin and B.I. Krasilov, High Temperature Corrosion and Protection of Ultra-Refractory Metals, Atomizdat, 1977, 224 (in Russian).

11. V.A. Lavrenko and Yu.G. Gogotsi, Corrosion of Structural Ceramics, Metallurgiya, 1989, 199 (in Russian).

12. J.P. Girardeau-Montaut, M. Afif, C. Girardeau-Montaut, S.D. Moustaïzis and N. Papadogiannis, Aluminium electron-phonon relaxation-time measurement from subpicosecond nonlinear single-photon photoelectric emission at $248 \mathrm{~nm}, J$. Appl. Phys., 1996, 62, 3-6. doi: 10.1007/BF01568079

13. S.N. Kostenkov, E.V. Kharanzhevskii and M.D. Krivilev, Determination of characteristics of laser radiation interaction with nanocomposite powder materials, Phys. Met. Metallogr., 2012, 113, 93-97. doi: 10.1134/S0031918X12010061

14. S.M. Reshetnikov, E.V. Kharanzhevskii and M.D. Krivilev, Corrosion-Electrochemical Behavior of Composite Layers Produced by Laser Sintering of Nanoscale Iron-Nickel Powders, Prot. Met. Phys. Chem. Surf., 2012, 48, no. 7, 729-734.

15. CRC Handbook Chemistry and Physics, ed. D.R. Lide., CRC Press. 2008-2009, 4-53.

16. M.D. Krivilyov, E.V. Kharanzhevskii, V.G. Lebedev, D.A. Danilov, E.V. Danilova and P.K. Galenko, Synthesis of Composite Coatings using Rapid Laser Sintering of Metallic Powder Mixtures, Phys. Met. Metallogr., 2013, 114, no. 10, 799-820.

17. I.L. Rozenfel'd, Ingibitory korrozii (Corrosion inhibitors), 1977, Moscow, Khimiya (in Russian).

18. Ya.G. Avdeev, M.V. Tyurina and Yu.I. Kuznetsov, Protection of low-carbon steel in phosphoric acid solutions by mixtures of a substituted triazole with sulfur-containing compounds, Int. J. Corros. Scale Inhib., 2014, 3, no. 4, 246-253. doi: 10.17675/23056894-2014-3-4-246-253

19. N.A. Gladkikh, M.A. Maleeva, L.B. Maksaeva, M.A. Petrunin, A.A. Rybkina, T.A. Yurasova, A.I. Marshakov and R.Kh. Zalavutdinov, Localized dissolution of carbon steel used for pipelines under constant cathodic polarization conditions. Initial stages of defect formation, Int. J. Corros. Scale Inhib., 2018, 7, no. 4, 683-696. doi: 10.17675/2305-6894-2018-7-4-14

20. D.O. Chugunov, A.A. Chirkunov and Yu.I. Kuznetsov, The effect of trialkoxysilanes on the passivation of mild steel surface modified with a zinc-phosphonate solution, Int. J. Corros. Scale Inhib., 2020, 9, no. 2, 757-770. doi: 10.17675/2305-6894-2020-9-2-23 